\title{
Differential regulation of transcription preinitiation complex assembly by activator and repressor homeo domain proteins
}

\author{
F. Brad Johnson and Mark A. Krasnow ${ }^{1}$ \\ Department of Biochemistry, Stanford University, Stanford, California 94305 USA
}

Different eukaryotic transcription factors can act through the same upstream binding site to differentially regulate target gene expression, but little is known of the underlying mechanisms. Here, we show that Ultrabithorax and even-skipped homeo domain proteins (UBX and EVE) of Drosophila melanogaster exert active and opposite effects on in vitro transcription when bound to a common site upstream of a core promoter. Both the activator UBX and the repressor EVE affect the extent but not the rate constant of preinitiation complex (preIC) formation. Both regulators act early in preIC assembly and are dispensable later. Assembling complexes become resistant to regulation by the bound proteins, but activation by UBX is restored upon ATP or dATP addition, and regulation by both proteins is restored after the addition of all four nucleoside triphosphates and transcription initiation. The results establish that upstream activators and repressors can function by fundamentally similar mechanisms, by differentially regulating an early step in preIC assembly, leading to formation of functionally distinct transcription complexes. A subsequent step renders mature complexes transiently refractory to activation and repression. Implications for the mechanism of transcription complex assembly and turnover and its regulation are discussed, including a new role for ATP in turnover.

[Key Words: Transcriptional activation; transcriptional repression; homeo domain proteins; Drosophila; Ultrabithorax; even-skipped]

Received June 12, 1992; revised version accepted August 10, 1992.

Families of transcription factors that bind to the same cis-regulatory site but with different regulatory effects are common in eukaryotes. A prominent example is the homeo domain proteins of Drosophila melanogaster, a large family of regulators with diverse developmental roles yet surprisingly similar in vitro DNA-binding specificities (for review, see Hayashi and Scott 1990). The mechanistic basis for the differential function of regulators bound to a common site is poorly understood, although in some instances it is thought to involve differing interactions of the bound transcription factors with neighboring transcription factors or with the general transcriptional machinery. Here, we investigate the mechanisms by which two $D$. melanogaster homeo domain proteins activate and repress basal transcription in vitro from a common upstream promoter site.

Our experiments involve the well-studied homeo domain proteins UBX Ib (hereafter, UBX) and EVE, encoded by the Ultrabithorax $(U b x)$ and even-skipped (eve)

\footnotetext{
${ }^{1}$ Corresponding author.
}

genes. eve is required for proper segment formation, and it also plays a role in the development of the nervous system and visceral mesoderm (Nüsslein-Volhard et al. 1985; Doe et al. 1988; Tremml and Bienz 1989). Ubx is a homeotic gene that acts primarily in the posterior thoracic and anterior abdominal region of the animal to specify segmental specializations of various tissues (Lewis et al. 1978; Hogness et al. 1985; for review, see Beachy 1990). The expression of certain presumptive UBX and EVE target genes is altered in $U b x^{-}$and eve $e^{-}$ mutant embryos (e.g., Hafen et al. 1984; Harding et al. 1986), respectively. Cell culture cotransfection experiments and in vitro transcription experiments indicate that these proteins act principally by binding to their target genes and activating or repressing transcription, although UBX may also have DNA-binding-independent regulatory functions (E. Parker, E. Saffman, and M.A. Krasnow, unpubl.). In cotransfection experiments, UBX stimulated or repressed transcription from different natural promoters that are targets during development (Krasnow et al. 1989), and it also stimulated transcription from simple synthetic target genes composed of ho- 
meo domain-binding sites fused to heterologous promoters (Thali et al. 1988; Krasnow et al. 1989; Sampson et al. 1989). In similar studies, EVE repressed transcription from the $U b x$ promoter and prevented activation by several different homeo domain proteins at a heterologous promoter (Biggin and Tjian 1989; Han et al. 1989). Two of these reactions, stimulation of a simple target promoter by UBX and repression of the Ubx promoter by EVE, have been reconstructed in vitro and provide simplified systems to investigate the regulatory mechanisms of these proteins (Biggin and Tiian 1989; Johnson and Krasnow 1990).

There are many steps in transcription by RNA polymerase II, and, in principle, any step could be a point of control by promoter-selective transcription factors such as UBX or EVE. Some activators can counteract repression caused by nucleosome formation or binding of histone $\mathrm{Hl}$ to the template DNA (for review, see Kornberg and Lorch 1991), a mechanism termed antirepression (Croston et al. 1991). Activators can also function more directly to regulate aspects of transcription preinitiation complex (preIC) formation or function, or transcript elongation (e.g., Sawadogo and Roeder 1985; Hai et al. 1988; Rougvie and Lis 1988; Lin and Green 1991); steps in initiation, in termination, and in reuse of templates in subsequent rounds of transcription remain as possible control points. PreICs are operationally defined as the protein-promoter complexes that form in the absence of nucleoside triphosphates (NTPs) and rapidly initiate transcription upon addition of NTPs. PreIC assembly involves at least six general transcription factors, including the TATA-binding factor and RNA polymerase II (for review, see Roeder 1991). Under typical in vitro conditions, preIC formation is slow with half-times of several minutes or more, whereas the steps that follow NTP addition, including the ATP-dependent formation of an activated preIC, initiation, and elongation, are much faster, with a combined half-time of only seconds for short transcription units (Hawley and Roeder 1985; Conaway and Conaway 1988; Kadonaga 1990; see Materials and methods). Functional assays indicate that the mammalian DNA-binding activating transcription factor (ATF) and upstream stimulating factor/major late transcription factor (USF/MLTF), and the yeast GAL4 protein derivative GAL4-AH modulate early or intermediate steps in preIC formation (Hai et al. 1988; Workman et al. 1990; Lin and Green 1991). Repressors can function by simply blocking the binding of general factors to the core promoter (e.g., Rio et al. 1980; Ohkuma et al. 1990a; Kato et al. 1991) or by inhibiting the DNA binding or function of sequence-specific activators (e.g., Lue et al. 1987; Keleher et al. 1988; Han et al. 1989; Okhuma et al. 1990b; Jaynes and O'Farrell 1991). Another widely held mechanism for upstream repressors involves an active effect on the general transcription machinery analogous but opposite to the effects of upstream activators on preICs, but this mechanism has not been established (Biggin and Tjian 1989; Levine and Manley 1989).

For any transcription factor that regulates preIC assembly or function, several important mechanistic ques- tions arise. First, does the regulator affect the rate of preIC assembly, the extent of preIC assembly (i.e., the fraction of templates in the reaction that assemble preICs), or the activity of the preIC so as to modulate the frequency or probability of productive initiation from the complex? Second, is the continued presence of the bound regulatory protein required for regulation, for example to stabilize or destabilize the preIC, or is it required only transiently during preIC assembly? Third, is regulation possible once the steady-state level of preICs has been reached? Fourth, is the regulatory effect lost after initiation and the first round of transcription, and are there fresh opportunities for regulation in subsequent cycles? Answers to the first two questions have begun to emerge for a few activators. USF/MLTF and the plant transcription factor TGAla have been shown to increase the extent of preIC formation (Carcamo et al. 1989; Katagiri et al. 1990; Workman et al. 1990), and the same is likely true for the mammalian activators $\mathrm{Sp} 1$ and DAP, although the evidence is less direct (Schmidt et al. 1989; Ayer and Dynan 1990). Also, ATF and TGAla are thought to be required only transiently for regulation, as after preIC assembly the regulators can apparently be titrated away from the template without abolishing their regulatory effect (Hai et al. 1988; Katagiri et al. 1990). And, finally, there is some evidence suggesting that USF cannot activate transcription once the template has been incubated with general transcription factors to allow preIC formation (Workman et al. 1990). None of these questions has been addressed for upstream repressors.

In this report we examine how UBX and EVE function in vitro at a simple target gene. We show that these regulators exert active and opposite effects on basal transcription when bound to a common upstream promoter site. Both the activator UBX and the repressor EVE are shown to regulate preIC assembly, and then the mechanistic issues raised above are addressed for each regulator. The results reveal an underlying mechanistic unity between upstream activators and repressors and provide new insights into the regulated assembly of transcription complexes and their turnover.

\section{Results}

UBX activates and EVE represses transcription of a simple target gene

A purified UBX protein produced in Escherichia coli can stimulate transcription from certain target promoters in vitro in nuclear extracts of $D$. melanogaster cultured $\mathrm{Kc}$ cells (Johnson and Krasnow 1990). Several constructs with different homeo domain-binding sites were activated by UBX; the simplest contained homeo domainbinding sites fused upstream of sequences extending from the TATA box to the transcriptional start site $(-33$ to +3 ) of the $D$. melanogaster Alcohol dehydrogenase $(A d h)$ distal promoter. Purified EVE protein can repress transcription of the $U b x$ promoter in vitro in a binding site-dependent manner in nuclear extracts derived from D. melanogaster embryos (Biggin and Tjian 1989). Be- 
cause UBX and EVE proteins display overlapping DNAbinding specificities in vitro, we tested EVE protein on the same template and under the same experimental conditions used for UBX, to determine whether the different reported regulatory activities were the result of differences in their intrinsic activities or differences in the templates or reaction conditions employed. Figure 1A shows that in contrast to the severalfold activation of the simple target gene observed with UBX (lane 3), purified EVE protein repressed transcription severalfold (lane 2). As with UBX, there was no effect of EVE under these conditions on the internal control template that lacks the homeo domain-binding sites. Similar results were obtained using embryo nuclear extracts instead of Kc cell nuclear extracts (Fig. 1B). Similar results with EVE have also been obtained using embryo extracts and related templates with different homeo domain-binding sites (M. Biggin, pers. comm.). These results show that UBX and EVE exert independent and opposite effects on transcription from a common upstream site. Neither effect requires any natural promoter elements outside the binding sites and core promoter sequences, and the specific sequence of the homeo domain-binding site is not critical for differential regulation.

\section{$U B X$ and EVE appear to regulate transcription by active mechanisms}

To begin to address the question of how these two pro-

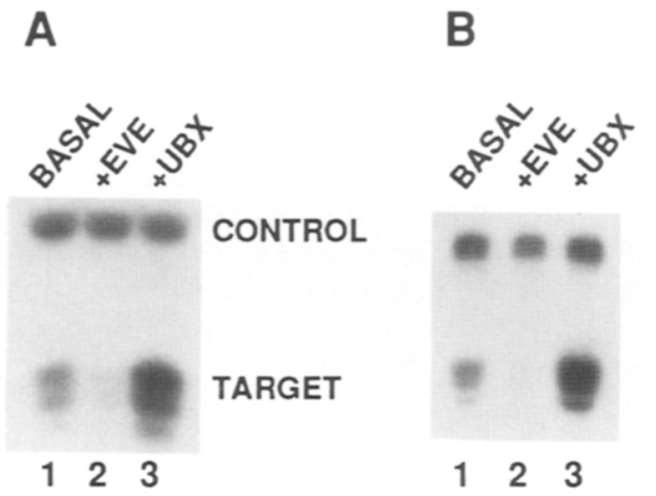

Figure 1. Effects of UBX and EVE on transcription of a simple target gene. $(A)$ In vitro transcription reactions $(25 \mu l)$ were carried out for $30 \mathrm{~min}$ at $22^{\circ} \mathrm{C}$ under standard conditions using $\mathrm{Kc}$ cell nuclear extracts and no additional proteins (lane 1), $300 \mathrm{ng}$ of EVE protein (lane 2), or $170 \mathrm{ng}$ of UBX protein (lane 3). Reactions contained $\mathrm{p}\left(\mathrm{U}+{ }_{2} \mathrm{D}-33 /+3 \mathrm{DNA}\right.$ at $10 \mu \mathrm{g} / \mathrm{ml}$ as the target template and $\mathrm{pD}-33 /+23 \mathrm{DNA}$ at $10 \mu \mathrm{g} / \mathrm{ml}$ as an internal control template. The target contains $D$. melanogaster Adh promoter sequences from -33 to +3 and the internal control contains sequences from -33 to +23 ; the target also contains two copies of the homeo domain-binding site oligonucleotide $5^{\prime} \mathrm{CATG}(\mathrm{AAT})_{12}$, abbreviated $\mathrm{U}+$, inserted at -47 . Transcripts were analyzed by primer extension; extension products of transcripts from the target and control templates are indicated. $(B)$ Reactions were carried out as in $A$ except that $D$. melanogaster embryo nuclear extracts were used in place of $\mathrm{Kc}$ cell nuclear extracts. teins exert opposite effects from a common site, we considered the possibility that one or both proteins might be acting by indirect or passive mechanisms, that is, those that require only occupancy of the binding site by the regulator. The experiments with the simple target gene described above, together with experiments with similar target genes in a different vector background (data not shown), ruled out indirect mechanisms involving sequence-specific activators and repressors that bind outside the homeo domain-binding sites and the core promoter region. Also, neither effect appears to involve factors in the extract that bind to the homeo domainbinding sites because (1) no such activity has been detected in the extracts in DNase I protection experiments (F.B. Johnson and M.A. Krasnow, unpubl.), (2) the presence of homeo domain-binding sites does not influence basal promoter activity appreciably (Johnson and Krasnow 1990), and (3) the specific homeo domain-binding site used is not critical (see above). We also considered two other possible indirect or passive mechanisms for these proteins: antirepression of nonspecific binding inhibitors by UBX and occlusion of general transcription factors by EVE.

The stimulatory activity of transcription factors that function by antirepression is abolished or reduced when basal transcription is elevated by removing the inhibitors, for example, by fractionation of the extracts or by addition of nonspecific competitor DNA (Abmayr et al. 1988; Kerrigan et al. 1991). We therefore examined regulation by UBX over a range of DNA concentrations, using a low fixed concentration of template DNA (4 $\mu \mathrm{g} /$ $\mathrm{ml}$ ) and variable amounts of pUC18 DNA as nonspecific competitor. Basal transcription was enhanced by competitor up to a total DNA concentration of $20-40 \mu \mathrm{g} / \mathrm{ml}$, indicating the presence of titratable DNA-binding inhibitors in the extracts (data not shown). However, at all DNA concentrations tested, including those at or above the optimal, the stimulatory effect of UBX remained constant (data not shown). This indicates that antirepression does not contribute to the UBX stimulatory effect under these conditions. Rather UBX may be acting more directly on the general transcriptional machinery, perhaps by enhancing the binding of core promoter factors or increasing their activity once bound.

We also considered whether EVE might repress transcription by sterically interfering with the binding of general transcription factors because the homeo domainbinding sites, at -47 , lie reasonably close to the core promoter of the target. If so, EVE would have to extend beyond the binding sites and occlude sequences closer to the promoter than does UBX. The following two results make the simple occlusion mechanism unlikely. First, EVE repressed and UBX activated transcription of templates in which the binding sites were placed farther upstream at -58 or -66 , demonstrating that the precise position of the binding sites near the promoter was not critical for regulation (Fig. 2A). Second, DNase I protection experiments were carried out with EVE and UBX proteins bound to the various supercoiled templates under the in vitro transcription conditions, using an indi- 
A

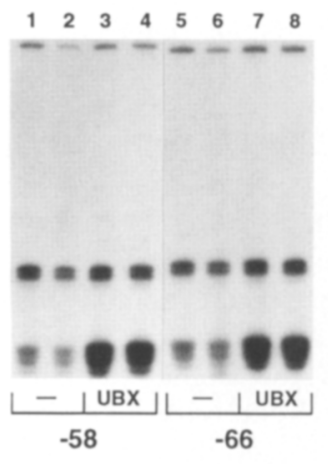

$\begin{array}{llllllll}9 & 10 & 11 & 12 & 13 & 14 & 15 & 16\end{array}$

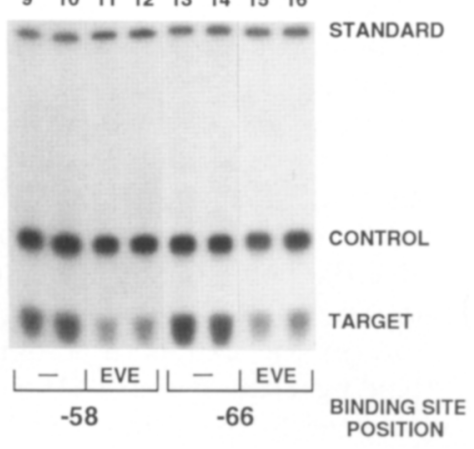

B

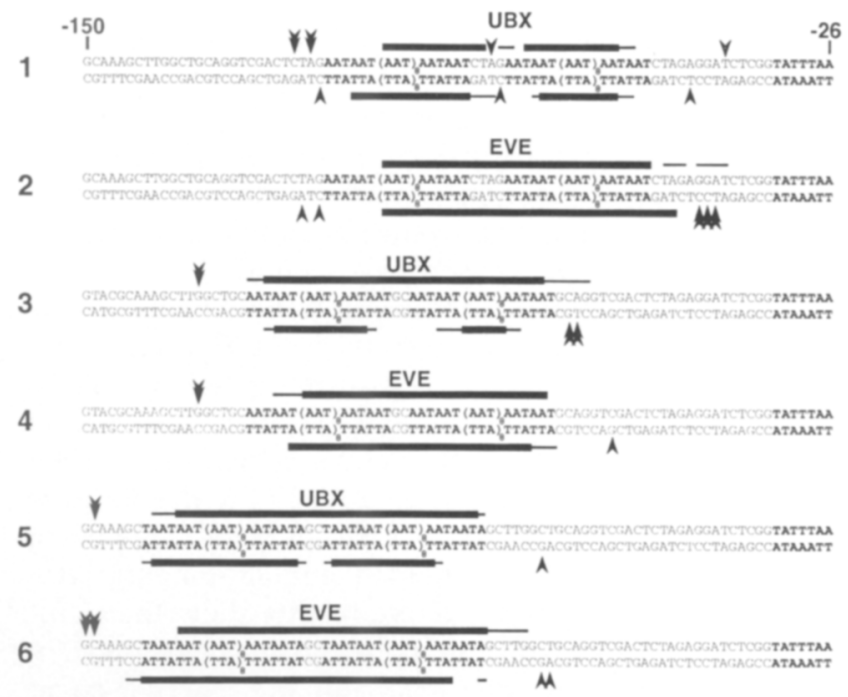

Figure 2. Transcriptional regulation and DNA binding by UBX and EVE at different upstream promoter positions. $|A|$ Transcriptional effects of UBX and EVE at different positions. Duplicate transcription reactions were carried out under standard conditions except that the target constructs contained homeo domain-binding sites either 58 bp (lanes 1-4 and 9-12) or 66 bp (lanes 5-8 and 13-16) upstream of the $A d h$ transcription start site. Reactions contained either no added homeo domain protein (lanes $1,2,5,6,9,10,13,14$ ), $170 \mathrm{ng}$ of UBX (lanes 3,4,7,8), $300 \mathrm{ng}$ of EVE (lanes 11,12), or $400 \mathrm{ng}$ of EVE (lanes 15,16). Similar effects on the different templates were observed with either 300 or $400 \mathrm{ng}$ of EVE (data not shown). (Standard) Primer extension products that derive from a standard amount of a synthetic RNA added after the transcription reaction as a control for variability in the primer extension analysis. (B) Summary of DNase I protection experiments. DNase I protection experiments were carried out under the in vitro transcription conditions, and an indirect end-labeling technique was used to visualize both DNA strands of the templates. Reactions contained $170 \mathrm{ng}$ of UBX (rows 1,3,5) or $300 \mathrm{ng}$ of EVE protein (rows 2,4,6). The homeo domain-binding sites of the templates are positioned at -47 (rows 1,2 ), -58 (rows 3,4 ), or -66 (rows 5,6 ). The extent of protection at the edges of the footprints varied by a few nucleotides in different experiments; representative experiments are shown. Positions of strong and weak protection by UBX or EVE are indicated by thick and thin lines, respectively, and positions of strong or weak enhancement are indicated by double and single arrowheads, respectively. The homeo domain-binding sites and the TATA box are shown in boldface type; the numbers indicate distances in nucleotides from the transcription start site. No other alterations in the DNase I cleavage patterns by the proteins were detected as far as $100 \mathrm{bp}$ downstream of the TATA box.

rect end-labeling technique (Gralla 1985) to visualize the digested template DNA. Although the patterns of protected and enhanced cleavages indicate that both bound proteins extended somewhat beyond the binding site sequences (Fig. 2B), the critical finding was that EVE could repress transcription when bound farther from the promoter than positions at which UBX bound and activated transcription. It is therefore unlikely that EVE simply blocks access of general transcription factors to the promoter. This conclusion is supported by experiments described in the next section, which indicate that EVE is required only transiently during preIC assembly for regulation, a result incompatible with a simple occlusion mechanism. Instead, we favor a model in which EVE binds to the target and then affects the general transcription factors in a manner analogous to that proposed for UBX, but decreasing their promoter affinity or diminishing their activity once bound.

\section{UBX and EVE function during preIC assembly}

To begin to define when in the transcription reaction UBX and EVE act, staged reactions were carried out in which the regulatory proteins were added either before or after preICs had formed. When the regulators were added after preIC formation, the incubations were continued for an additional 8 or $80 \mathrm{~min}$ to allow them to bind to the target and function. A low concentration $[0.035 \%(\mathrm{wt} / \mathrm{vol})]$ of the detergent Sarkosyl was then added followed $30 \mathrm{sec}$ later by NTPs; these conditions prevent new preICs from forming but allow a single round of transcription from preICs that had formed previously (Hawley and Roeder 1985; see Materials and methods). As shown in Figure 3A, both proteins had full regulatory activity when added to the staged reactions before preIC formation. In contrast, when UBX or EVE was added to staged reactions after preIC formation, neither had any effect on transcription, even when the proteins were incubated with the preformed complexes for 80 min before the addition of Sarkosyl and NTPs (Fig. $3 \mathrm{~A}$; data not shown). Similar results were obtained in experiments using embryo nuclear extracts (data not shown). Thus, following preIC assembly, transcription is resistant to regulation by UBX and EVE (also see below). This strongly suggests that both the activator UBX and the repressor EVE affect the assembly of preICs and not the activity or stability of the fully formed complexes or the subsequent initiation and elongation phases of transcription.

The above experiment does not exclude the possibility 
A

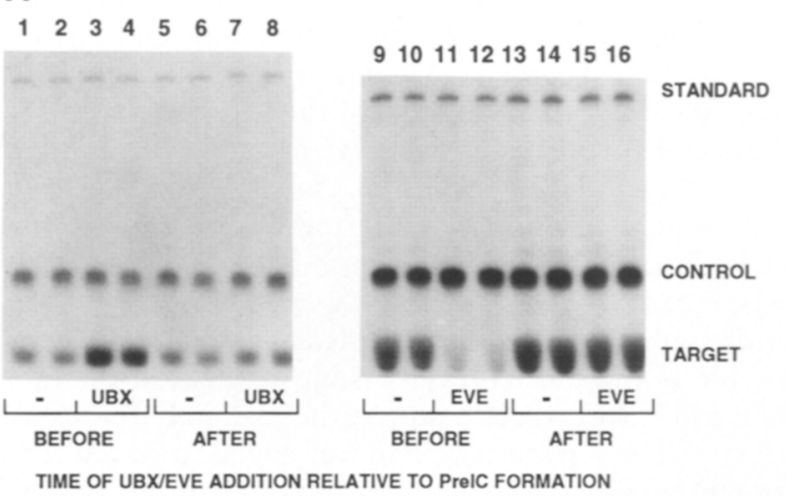

B

$\begin{array}{llllllllllll}1 & 2 & 3 & 4 & 5 & 6 & 7 & 8 & 9 & 10 & 11 & 12\end{array}$

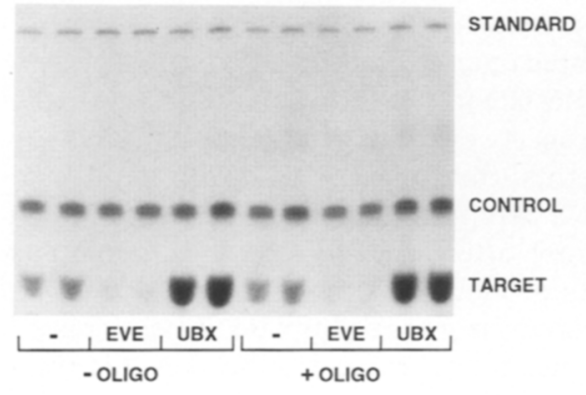

C

$\begin{array}{llllllllllll}1 & 2 & 3 & 4 & 5 & 6 & 7 & 8 & 9 & 10 & 11 & 12\end{array}$

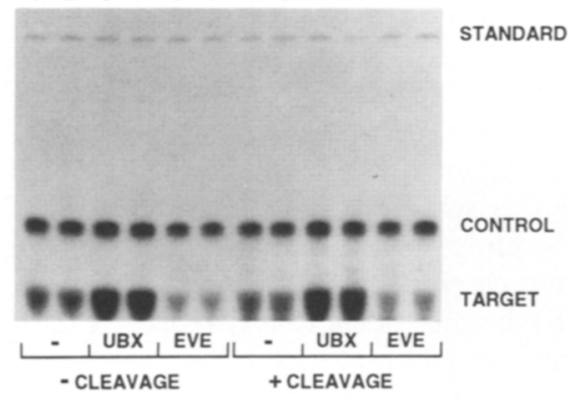

Figure 3. UBX and EVE act during preIC assembly. (A) Effects of UBX and EVE before and after preIC formation. Templates were incubated with nuclear extracts under standard conditions except that NTPs were omitted to prevent transcription initiation but allow preIC formation; incubations were for $120 \mathrm{~min}$ to allow the assembly reactions to reach completion. As indicated, UBX or EVE proteins were either added to the templates $8 \mathrm{~min}$ before the incubation with extract (before preIC formation), or they were added after the 120 min incubation with extract and then incubated for an additional $8 \mathrm{~min}$ (after prelC formation) or $80 \mathrm{~min}$ (data not shown). Sarkosyl $[0.035 \%(\mathrm{wt} / \mathrm{vol})]$ and NTPs were then added, the incubations were continued for an additional 30 min, and transcripts were analyzed by primer extension. The addition of Sarkosyl prevents additional preICs from forming but allows a single round of transcription from preformed preICs. All reactions were performed in duplicate; control reactions without UBX or EVE are indicated by $(-1$. The $80-$ min postincubations with UBX or EVE gave the same results as the 8 -min postincubations. (B) Binding site oligonucleotides added after preIC assembly abolish template binding but not regulation by UBX and EVE. (Left) PreICs were assembled alone or with UBX or EVE, as indicated, under standard conditions except that embryo nuclear extracts were used. After preIC assembly, either a mock addition was made (lanes 1-6) or $1.8 \mu \mathrm{g}$ of a 36-bp oligonucleotide containing homeo domain-binding sites was added (lanes 7-12). The incubations were continued for $10 \mathrm{~min}$, and Sarkosyl and NTPs were added and the reactions completed as in A. (Right) DNase I protection experiments were carried out in a parallel set of reactions to monitor binding of UBX and EVE. After preIC formation and the 10 -min incubation in the presence or absence of the competitor oligonucleotide, DNase I was added for $40 \mathrm{sec}$. The reactions were stopped, and the cleavage products of the template were visualized by indirect endlabeling as in Fig. 2 using a probe for the noncoding strand. (Bent arrow) Transcription start site; (brackets) homeo domain-binding sites. (C) Cleavage of the template between the homeo domain-binding sites and the promoter after preIC assembly does not affect regulation. PreICs were assembled alone or with UBX or EVE, as indicated, under standard conditions except that the target was the -66 template, which contains $P_{s t} \mathrm{I}$ and $\mathrm{XbaI}$ restriction sites between the homeo domain-binding sites and the core promoter. After preIC assembly, templates were either mock treated (lanes 1-6) or treated with excess $P$ stI and $X b a I$ restriction endonucleases at $22^{\circ} \mathrm{C}$ for $30 \mathrm{~min}$ (lanes $7-12$ ). Sarkosyl and NTPs were then added, and the reactions were completed as in A. Agarose gel electrophoretic analysis of aliquots of the reaction mixtures demonstrated that $\sim 95 \%$ of the templates in each reaction were cleaved by endonuclease treatment and that cleavage efficiency was not affected by UBX or EVE (data not shown).

that UBX and EVE must be present during preIC assembly but then exert their effects at a later step in the transcription reaction. To address this possibility, after preIC assembly but before the addition of NTPs, UBX and EVE were removed from the template by the addition of excess competitor oligonucleotide containing homeo domain-binding sites. As shown in Figure 3B (left), full regulation by both UBX and EVE was maintained after the addition of the competitor. DNase I protection experiments using indirect end-labeling of the template DNA confirmed that UBX and EVE were removed from the bulk of the templates under these conditions (Fig. 3B, right), although the possibility that UBX or EVE remained bound to a minor subset of templates in the reaction is not excluded. In a related set of experiments, we found that full regulation by both UBX and EVE was also maintained when, following preIC formation, the template DNA was cleaved by restriction endonucleases at sites that lie between the bound homeo domain proteins and the promoter (Fig. 3C). We conclude that UBX and EVE are not required following preIC assembly and that both function transiently during the assembly reaction. 
UBX and EVE modulate the efficiency of preIC assembly

The time course of preIC formation under basal conditions and in the presence of UBX or EVE is shown in Figure 4. Under basal conditions, preICs formed at the target promoter with apparent first-order kinetics and a half-time of $25 \mathrm{~min} ; ~ 3 \%$ of the templates formed productive complexes. These values are similar to those reported for other in vitro transcription systems, although preIC formation was somewhat slower under the conditions used here (Hawley and Roeder 1985, 1987; Kadonaga 1990). The UBX protein increased the production of preICs severalfold, whereas EVE had an equal but opposite effect. In both cases, preICs formed with apparent first-order kinetics and half-times indistinguishable from those of the basal reaction. Similar experiments using embryo nuclear extracts also demonstrated that UBX and EVE regulate the extent of preIC assembly /data not shown). Thus, both the activator UBX and the repressor EVE modulate the efficiency with which templates assemble into productive preICs and not the observed rate constant of assembly.

\section{Why does transcription become resistant to UBX} and EVE during preIC assembly?

As described in a preceding section, transcription was resistant to regulation by both UBX and EVE after the

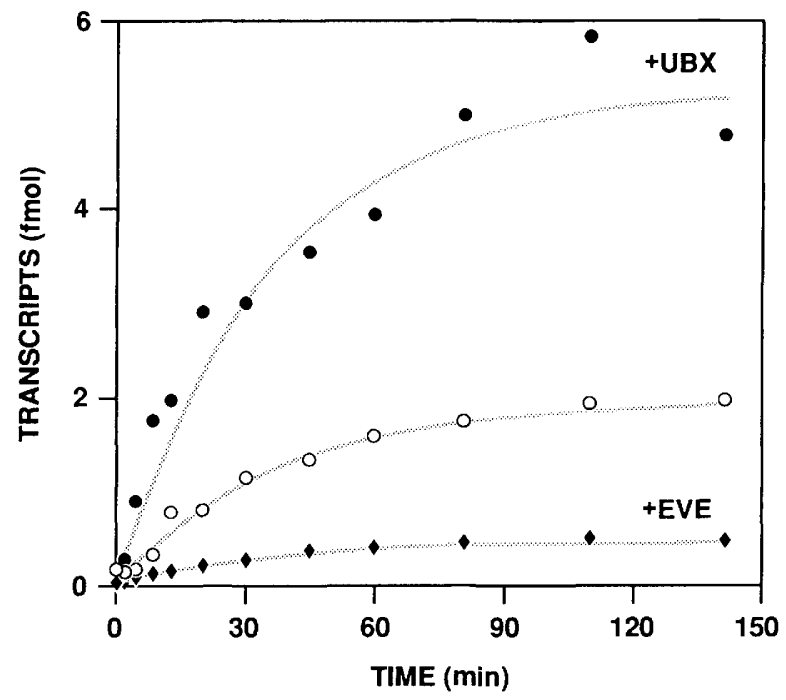

Figure 4. Time course of preIC formation in the presence of UBX and EVE. Templates were incubated with nuclear extracts and either $\operatorname{UBX}(\bullet), \mathrm{EVE}(\bullet)$, or no additional protein $(O)$ for the indicated times under standard conditions for preIC formation. Sarkosyl and NTPs were then added and the incubations were continued for an additional $30 \mathrm{~min}$. Transcript levels from the target template were quantitated and used as a measure of preIC formation. They are plotted along with a best-fit curve for a first-order reaction using the 10 earliest time points $\mid r>0.92$ for each curve). The half-times for preIC formation were 24,23 , or $25 \mathrm{~min}$ in the presence of UBX, EVE, or no additional protein, respectively.
preIC assembly reaction. This is somewhat surprising given that UBX and EVE affect the extent and not the rate constant of preIC assembly; a simple equilibrium effect should not be sensitive to the timing of regulator addition. However, if the regulated step in assembly is followed by an irreversible step, then the resultant products would not be susceptible to regulation. We therefore carried out the following experiments to test whether resistance to regulation by UBX and EVE results from formation of such regulator-resistant complexes and to exclude as the cause other possible changes in the template and extract factors during the assembly reaction.

First, when a fresh template was added to staged reactions after preIC formation was complete on the original template, transcription from the added template was fully stimulated by UBX and repressed by EVE (data not shown). This demonstrates that all extract factors required for regulated transcription were present and none had been inactivated or critically depleted during the initial incubation. Resistance to regulation must therefore reside in some property of the original template (and any stably bound factors) that is acquired during preIC formation. Second, a template recycling experiment was carried out in which after preIC formation the products were treated with proteinase $\mathrm{K}$ and extracted with phenol to remove proteins from the template. When retested in a standard transcription reaction, the recycled template was fully active for both basal and regulated transcription (data not shown). This shows that the template was not irreversibly modified during the assembly reaction and that resistance must reside in extract factors that become associated with the template and not the template DNA itself. Third, DNase I protection experiments using indirect end-labeling showed that there was no significant diminution in the ability of UBX or EVE to bind and protect the target sites from DNase I digestion during or after preIC assembly (Fig. 5). The bulk of the target templates therefore remain accessible to UBX and EVE throughout the reaction.

We conclude that the resistance to regulation by UBX and EVE results from extract factors that become stably associated with the target template during preIC assembly. These factors do not prevent binding of the homeo domain proteins to the target; rather, they somehow prevent the assembly of additional preICs by the activator UBX and the inactivation or disassembly of preICs by the repressor EVE. An explanation that we suggest in the Discussion is that a productive or nonproductive transcription complex forms at each promoter during the assembly reaction, and these complexes become resistant to regulation during the assembly process.

The rate at which complexes become resistant to UBX and EVE was determined by adding the homeo domain proteins to the reactions at various times after the start of preIC formation. The regulatory effects of both UBX and EVE gradually diminished during preIC formation with apparent first-order kinetics and a half-time of 15 min. (Fig. 6A,B). The similar time course for both proteins suggests that a common event renders complexes resistant to UBX and EVE. Also, because sensitivity is 

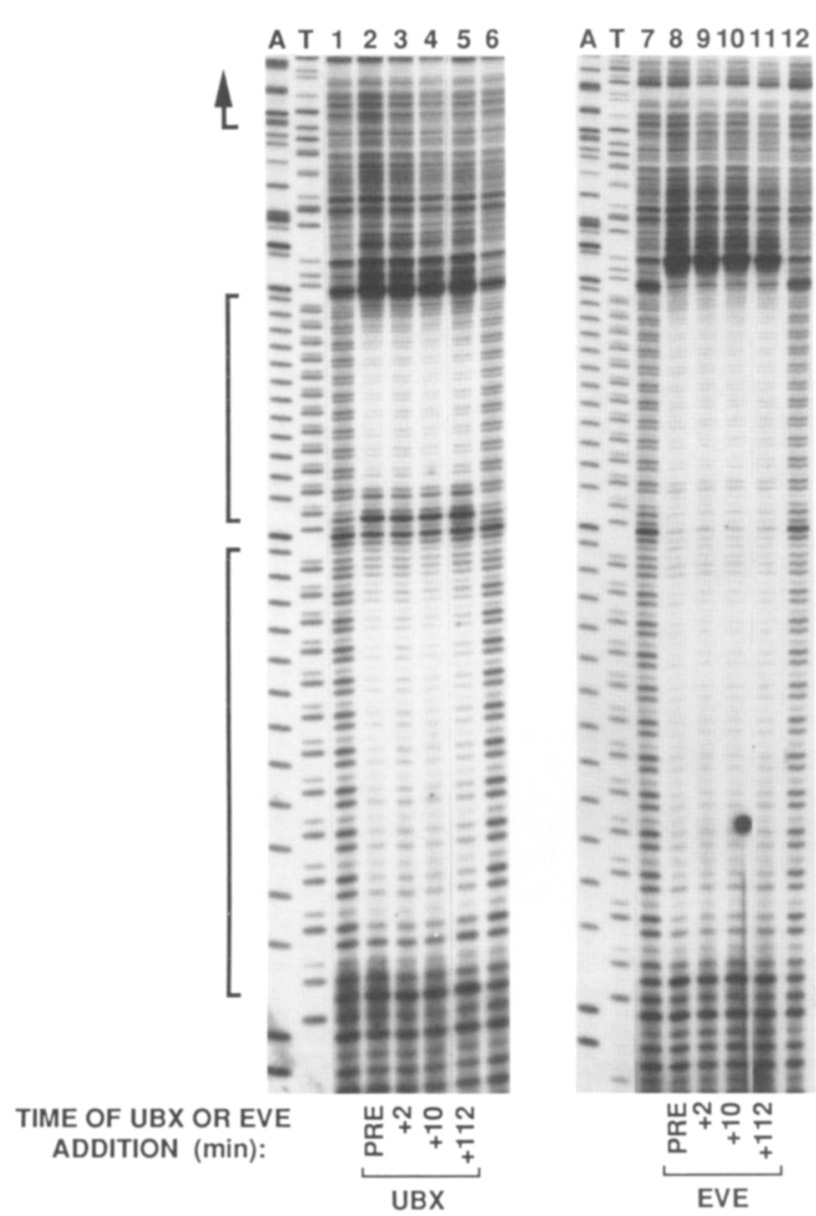

Figure 5. Template accessibility to UBX and EVE does not change during preIC formation. Templates were incubated with the nuclear extracts under standard conditions for preIC formation. After $2 \mathrm{~min}$ (lanes 3,9), $10 \mathrm{~min}$ (lanes 4,10), or $112 \mathrm{~min}$ (lanes 5,11 ) of preIC formation, UBX or EVE protein was added and the incubations were continued for $8 \mathrm{~min}$. For comparison, the homeo domain proteins were either prebound to the templates for $8 \mathrm{~min}$ before a 10 -min incubation with the extract (lanes 2,8), or the templates were incubated with extract alone for $10 \mathrm{~min}$ (lanes 1,7 ) or $120 \mathrm{~min}$ (lanes 6,12 ). Binding to the target DNA $\left(\mathrm{p}(\mathrm{U}+)_{2} \mathrm{D}-33 /+3\right)$ was assayed by DNase I protection and indirect end-labeling using a probe for the noncoding strand. Lanes $A$ and $T$ are dideoxy sequencing ladders of the template DNA. (Bent arrow) Transcription start site; (brackets) homeo domain-binding sites.

lost significantly faster than the rate at which complete preICs form (Fig. $6 \mathrm{C}$ ), the step or steps that render the complexes refractory to UBX and EVE must be distinct from and precede the final step in preIC formation.

\section{Resensitization to regulation by $U B X$ and EVE after preIC assembly}

Although the above experiments demonstrated that UBX- and EVE-resistant complexes arise during preIC assembly, the assays were performed under single-round transcription conditions and so did not address whether the resistant complexes remain fixed at the promoter in subsequent rounds of transcription. D. melanogaster embryo nuclear extracts support multiple rounds of transcription from a template for at least several hours (Kadonaga 1990; F.B. Johnson and M.A. Krawnow, unpubl.); Kc cell nuclear extracts are much less robust in multiround transcription (F.B. Johnson and M.A. Krasnow, unpubl.). By using embryo extracts and by omitting the addition of Sarkosyl after preIC formation to allow multiple rounds of transcription, it was possible to assay the regulatory functions of UBX and EVE following the initial round of transcription. When UBX or EVE proteins were added to preassembled preICs under these conditions (Fig. 7A), they had no effect on the initial level of transcription, as expected, because the initial transcription derives from preformed preICs. However, subsequent transcription was increased in the presence of UBX and diminished in the presence of EVE. Furthermore, in other experiments we found that the rate of post-first-round transcription when UBX was added after preIC assembly was several-fold greater than that of the first and subsequent rounds under basal conditions, and the opposite was true for EVE (data not shown). This indicates that UBX enabled transcription from templates that were inactive in the first round, and EVE prevented transcription from templates that were previously active. Thus, although the homeo domain proteins did not regulate the activity of preformed preICs, sensitivity to the regulators was restored in subsequent rounds of transcription.

In the above experiments, resensitization to UBX and EVE may have resulted from the initiation of transcription from the preformed preICs, or alternatively, resensitization could have resulted from another activity that requires one or more of the added NTPs. To test this second possibility, preformed complexes were incubated with UBX or EVE and individual NTPs for $60 \mathrm{~min}$, followed by the addition of Sarkosyl and all four NTPs to allow a single round of transcription. Surprisingly, incubation of preformed complexes with ATP and UBX caused a large increase in first-round transcription (Fig. 7B, lane 81, comparable to the effect observed when UBX was added before preIC formation. In contrast, incubation of the preformed complexes with either UBX (lane 4) or ATP (lane 6) alone, or with UBX and CTP, GTP, or UTP (data not shown), had little effect. dATP, however, did substitute for ATP in the reaction (lane 12), whereas adenosine $5^{\prime}-O$ - (thio)triphosphate (ATP $\gamma$ S), an ATP ana$\log$ with a $\beta, \gamma$-phosphoanhydride bond resistant to hydrolysis, did not (data not shown). Only very low levels of repression by EVE were restored by the addition of any of the individual nucleoside triphosphates including ATP and dATP (lanes 3,7,11; data not shown). Similar results for both UBX and EVE were obtained in a parallel set of experiments testing ATP but using Kc cell nuclear extracts instead of the embryo extracts used in the above experiments (data not shown). Thus, ATP or dATP restores regulation of preformed complexes by UBX, and the effect is specific for an adenine nucleoside triphos- 
A

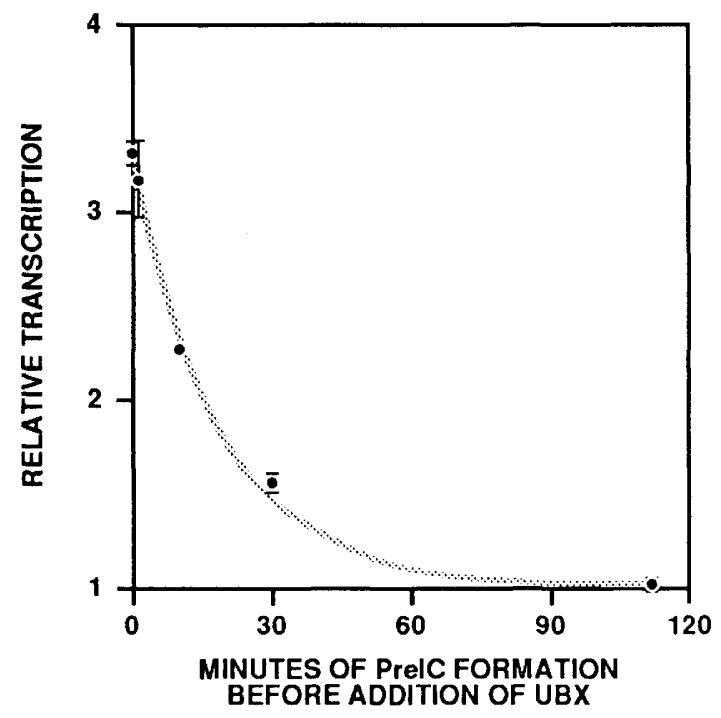

B

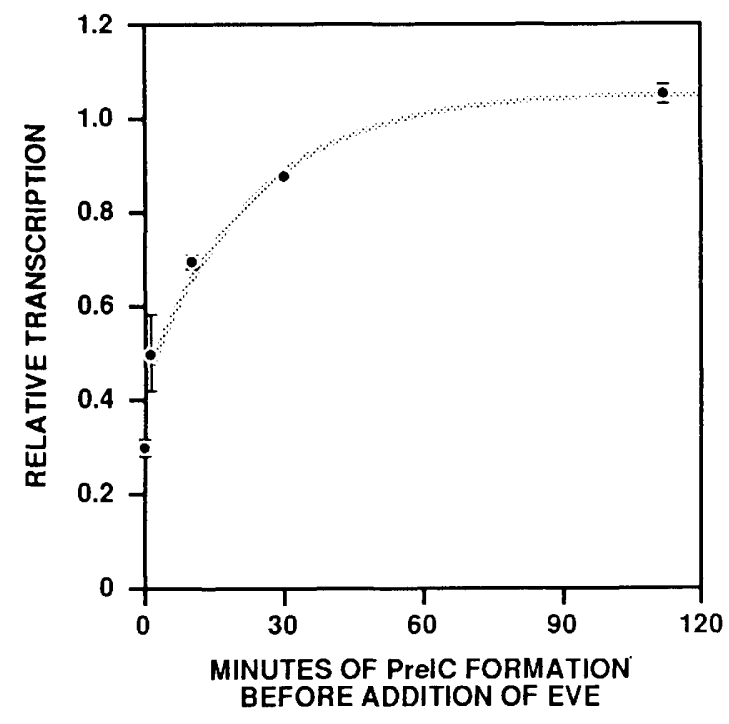

C

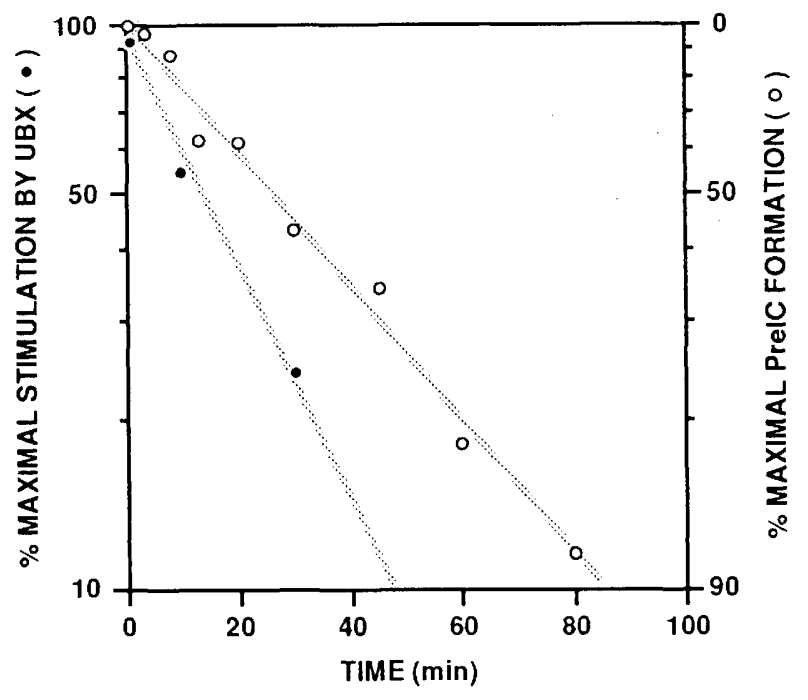

Figure 6. Time course of the loss of sensitivity to regulation by UBX and EVE. $(A, B)$ Templates were incubated with nuclear extracts under standard conditions for preIC formation. After the indicated duration of preIC formation, UBX or EVE protein was added and the incubations were continued to allow completion of preIC formation. After $120 \mathrm{~min}$ of total incubation time, Sarkosyl and NTPs were added and the incubations were continued for an additional $30 \mathrm{~min}$. Stimulation by UBX and repression by EVE were calculated as the relative amount of transcripts from the target and control templates in the presence of added homeo domain protein compared with their relative amount in control reactions with mock additions. Error bars indicate standard deviations of duplicate reactions, and best-fit curves for a first-order reaction using the four earliest time points are shown $\mid r=0.99$ for the UBX curve; $r=0.97$ for the EVE curvel. The half-time for loss of sensitivity was $15 \mathrm{~min}$ for both UBX and EVE. Binding of UBX and EVE to the templates is rapid under the reaction conditions with half-times of $<1$ min (data not shown) and therefore does not contribute substantially to the observed rates. $(C)$ Comparison of the rate of preIC formation to the rate of loss of regulation by UBX. Semilogarithmic plots are shown of the time course of the loss of sensitivity to $\operatorname{UBX}(0$; data from $A)$ and of preIC formation under basal conditions $(O$; data from Fig. 5). phate cofactor and may require hydrolysis of the $\beta, \gamma$ phosphoanhydride bond.

\section{Discussion}

We have shown that UBX and EVE homeo domain proteins can act through the same upstream binding sites in vitro with opposite effects on transcription. In each of the following ways the two regulatory proteins functioned in an analogous but opposite fashion. First, both bound proteins appeared to exert active effects on factors that assemble at the core promoter region and not on any sequence-specific or nonspecific DNA-binding proteins that act outside this region. Second, both proteins regulated transcription preIC formation, and they both affected the extent and not the observed rate constant of preIC formation. Third, both proteins had to be present early in preIC assembly to exert their effects and were dispensable once preIC assembly was complete. Fourth, the loss of sensitivity to both proteins during preIC formation resulted from formation of regulator-resistant complexes at the template, and the resistant complexes arose with a similar time course for the two proteins and at a rate significantly faster than that of preIC formation. Finally, after formation of the resistant complexes, regulation by both proteins was restored in subsequent rounds of transcription. These results demonstrate that an upstream repressor can function during preIC assembly and by a mechanism fundamentally similar to that of an upstream activator, revealing an underlying mechanistic unity between activators and repressors. Several important conclusions about the mechanism of transcription complex assembly and its regulation follow from these results, and they are incorporated into the scheme shown in Figure 8 and discussed below.

First, the fact that the extent of preIC formation can be 
A
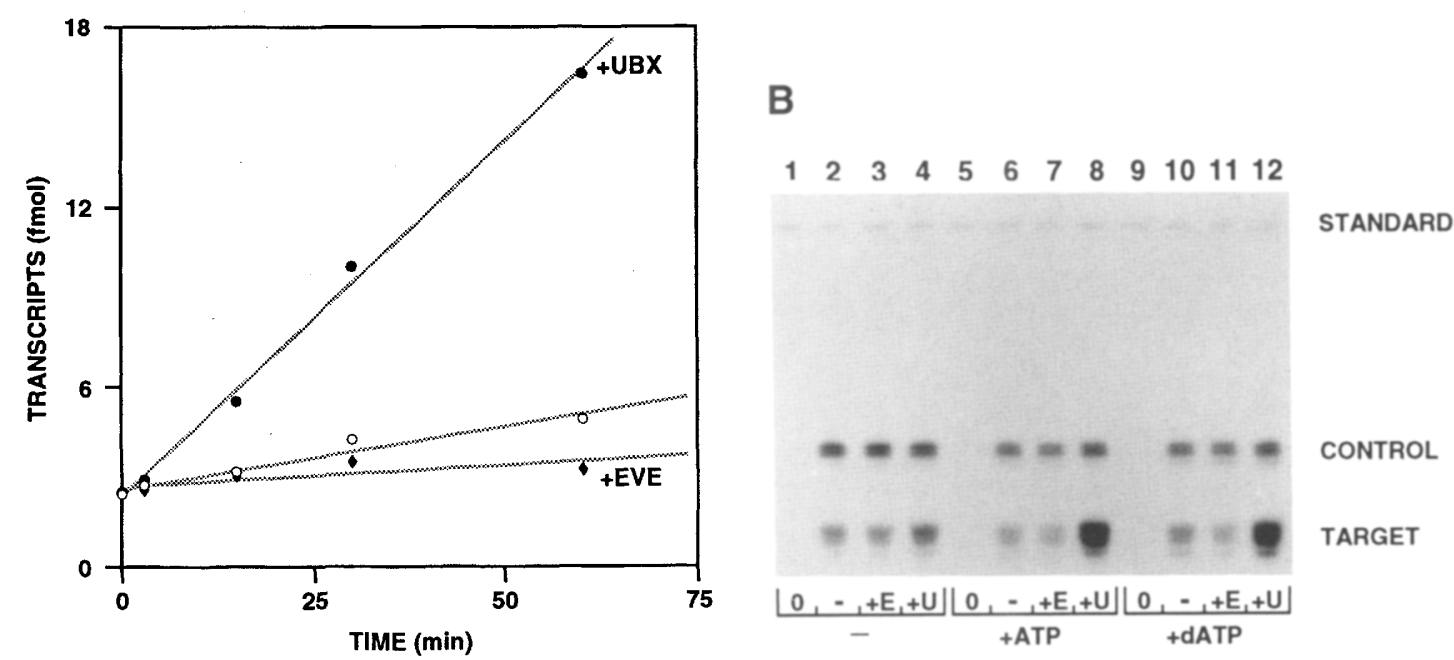

Figure 7. Resensitization of preassembled complexes to regulation by UBX and EVE. (A) Effects of UBX and EVE when added after preIC assembly under multiple-round transcription conditions. Templates were incubated under standard conditions for preIC formation except that embryo nuclear extracts were used in place of Kc cell extracts. After 105 min, which allows the assembly reactions to reach completion under these conditions (data not shown), UBX (O) or EVE ( $)$ was added, or a mock addition was made $(O)$, and the incubations were continued for $20 \mathrm{~min}$. NTPs were then added and the reactions were continued for the times indicated. For the time zero measurement, Sarkosyl was added to $0.035 \%(\mathrm{wt} / \mathrm{vol})$ just before the addition of NTPs and the incubation was continued for $30 \mathrm{~min}$ to allow accurate quantitation of a single round of transcription from the preformed preICs. The average transcription of target templates in duplicate reactions is shown along with best-fit curves generated by linear regression analysis. Standard deviations were $<10 \%$ of the average values. $|B|$ Resensitization of preassembled preICs to regulation by UBX in the presence of ATP or dATP. Templates were incubated with embryo nuclear extracts, as described above, to allow assembly of preICs. UBX (lanes 4,8,12) or EVE (lanes $3,7,11$ ) was then added, or a mock addition was made (lanes 1,2,5,6,9,10), and the incubations were continued. After 20 min, 500

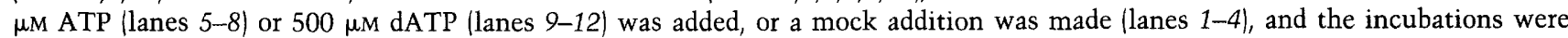
continued for an additional $60 \mathrm{~min}$. Sarkosyl $[0.035 \%$ (wt/vol)] and all four NTPs were then added $($ lanes $2-4,6-8,10-12)$, and the incubations continued for $30 \mathrm{~min}$. Lanes 1,5, and 9 are control reactions in which the addition of Sarkosyl and the four NTPs and the final incubation were omitted to establish that no transcription had occurred during the previous incubations with ATP and dATP.

modulated in both directions implies that there is a balance between productive and nonproductive transcription complexes during preIC assembly and that this balance is controlled by upstream regulators. While this balance might simply be modeled as a regulated equilibrium event in a linear assembly pathway, in Figure 8 it is represented as the partitioning of an intermediate along pathways leading to the formation of either productive

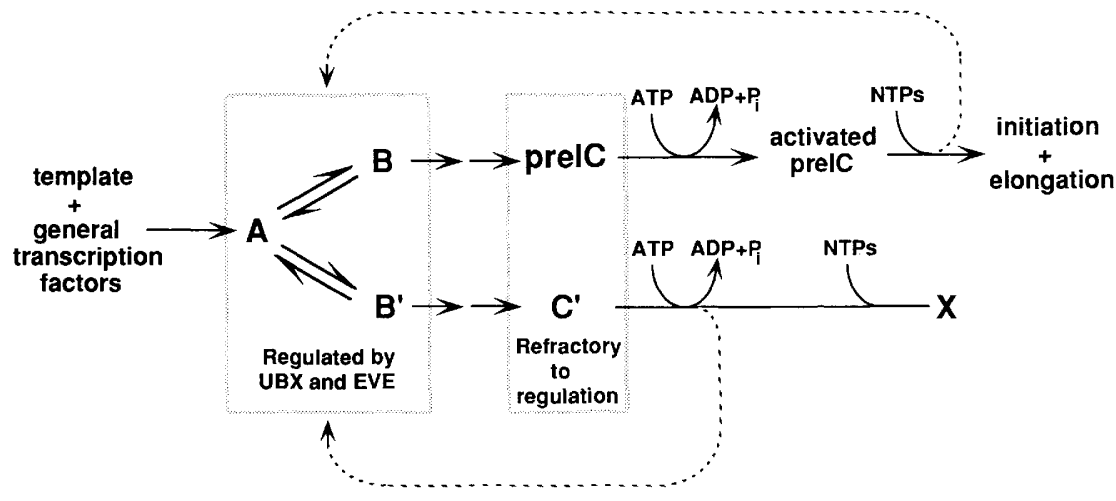
ases assembly along the productive or nonproductive branch, respectively. The complexes preIC and $\mathrm{C}^{\prime}$ are resistant to regulation by the bound homeo domain proteins because of a preceding irreversible step, but complexes are returned to a regulatable state upon addition of all four NTPs or, in the case of $\mathrm{C}^{\prime}$, just the addition of ATP. The broken lines indicate that the precise step to which promoter complexes are recycled is uncertain.

Figure 8. Scheme for preIC assembly and regulation by UBX and EVE. The assembly of general transcription factors at a promoter is shown as a bifurcating pathway in which the top branch is the previously defined pathway leading to formation of a productive preIC. A productive preIC is matured into an activated preIC in the presence of ATP, and transcription initiation and elongation ensue upon addition of all four NTPs. The bottom branch leads to formation of the nonproductive complex $\mathrm{C}^{\prime}$, which does not give rise to transcripts upon addition of NTPs. When UBX or EVE is bound to an upstream promoter site it bi- 
or nonproductive transcription complexes. The data suggest partitioning because it readily explains (1) how both productive and nonproductive complexes become resistant to regulation by upstream activators and repressors following preIC assembly (as detailed in the following paragraph), and (2) how regulatory effects persist when regulators are removed following preIC assembly. In molecular terms, the balance between pathways might correspond, for example, to an equilibrium between active and inactive conformations of a general transcription factor or to the presence or absence of a factor or factors in the complex. TFIIA and the recently described factor NC2, which compete for interaction with the TATAbinding subunit of TFIID and facilitate or prevent, respectively, formation of a productive preIC (Meisterernst and Roeder 1991), may be two such factors. The discovery of inhibitory factors such as NC2 has led to the proposal of a similar bifurcating assembly pathway (Roeder 1991), and the presence of such factors may account in part for the low basal efficiency of template utilization commonly observed in vitro. In the scheme of Figure 8, promoter-bound UBX and EVE drive the equilibrium between productive and nonproductive complexes in opposite directions, perhaps by allosterically altering or stabilizing binding of a target factor. The modulation of an equilibrium event in preIC assembly may be a general mechanism of upstream regulators, as USF/MLTF, TGA1a, and probably Sp1 and DAP all appear to increase the efficiency of preIC formation (Carcamo et al. 1989; Schmidt et al. 1989; Ayer and Dynan 1990; Katagiri et al. 1990; Workman et al. 1990).

The second implication of our results is that transcription complexes become refractory to regulation during preIC assembly. This conclusion is based on the following observations. First, although UBX and EVE modulate the extent of preIC assembly and not the observed rate constant, implying an equilibrium effect rather than a kinetic effect, both were ineffectual when added after preIC assembly. Second, the inability of UBX and EVE to act after preIC assembly did not result from the depletion of any required factors in the extract or from the inability of UBX or EVE to bind to the target promoter. Third, regulation could be restored by extraction of proteins from the template and the addition of fresh factors. Fourth, as elaborated below, regulation by UBX and EVE was restored in subsequent rounds of transcription, conditions that are known to cause partial or complete disassembly of productive preICs (Hawley and Roeder 1987; Van Dyke et al. 1988; Kadonaga 1990). These results indicate that a productive or a nonproductive complex forms at each template, and both types of complexes become resistant to regulation; resistance to the activator UBX implies that nonproductive complexes cannot be converted to productive complexes, whereas resistance to the repressor EVE implies that productive complexes cannot be converted to nonproductive complexes. One way in which assembling transcription complexes could become resistant to regulation is if the regulated step in preIC assembly or a subsequent step in the pathway is irreversible, as indicated in Figure 8. After the irreversible step, particular conformations or assemblages of factors would become fixed at a promoter and interconversion of productive and nonproductive complexes would be prevented. Although we prefer this scheme, we cannot distinguish it from alternative models in which resistance to regulation results from a concurrent process that is not an essential part of the assembly pathway. For example, resistance could result from the binding of a nonessential extract factor to both productive and nonproductive complexes at a site that is critical for regulation. Both classes of models explain how UBX and EVE modulate the extent, but not the observed rate constant, of preIC formation and also account for their inability to influence the distribution between active and inactive complexes after preIC formation is complete.

The third implication stems from the finding that regulation by UBX and EVE was restored in subsequent rounds of transcription; this indicates that resistant complexes are not permanently fixed at a promoter and that they are either modified or removed in the presence of NTPs. Under standard reaction conditions with NTPs present there must therefore be continual cycling between early, regulatable complexes and late, resistant transcription complexes at a promoter. Upstream activators and repressors such as UBX and EVE would have a fresh opportunity in each cycle to bias maturation along the productive or nonproductive branches of the pathway. There would be a transient but renewed requirement for the regulatory protein in each assembly cycle, and promoter activity would correspond to the fraction of assembly cycles that yield productive preICs. Dynamic cycles of assembly and turnover of promoter complexes are probably necessary in vivo, as there are only two copies of most genes in diploid cells and, hence, stable promoter complexes would not allow for rapid changes in the transcription rate.

According to the scheme of Figure 8, NTPs allow transcription from productive preICs and simultaneously restore repression by EVE, presumably because upon initiation the productive preICs partly or completely disassemble and reassembly is then subject to regulation anew. Restoration of regulation by UBX after NTP addition is a more surprising finding as it implies that the nonproductive, resistant complexes must also turn over under transcription conditions. We found that resensitization to UBX could occur in the absence of transcription if ATP or dATP was present; the other three NTPs were dispensable, and they did not efficiently substitute for ATP nor did ATP $\gamma$ S. Thus, in addition to the two established roles for ATP in transcription-maturation of a preIC into an activated preIC just before initiation and as a substrate in chain elongation-our results suggest a new and unexpected role for ATP: disassembly of nonproductive transcription complexes and resensitization to regulation by an upstream activator. Although the ATP-dependent effector in this process is unknown, we note that the new function displays the same specificity for an adenosine nucleoside triphosphate (ATP or dATP), and a hydrolyzable $\beta, \gamma$-phosphoanhydride bond 
as the ATP requirement for maturation of a preIC into an activated preIC (Bunick et al. 1982; Sawadogo and Roeder 1984; Conaway and Conaway 1988). This sug. gests that the same enzyme and catalytic event might be responsible for both disassembling nonproductive complexes and maturing productive complexes and thus may serve as a type of proofreading function for transcription complexes prior to initiation.

Our in vitro results provide a plausible biochemical mechanism by which regulatory proteins that bind to the same upstream site can effect different regulatory programs, namely by directing assembly of functionally distinct transcription complexes at a core promoter. Part of the developmental specificity of homeo domain proteins such as UBX and EVE may thus reside in their differential effects on core promoter factors, in addition to differences in interactions with other regulatory factors and differences in binding site selectivity that exist in vivo. It is easy to imagine a third class of proteins that would bind to the same simple target gene as UBX and EVE but with no effect on preIC formation, and some homeo domain proteins behave as transcriptionally inert DNA-binding proteins under certain experimental conditions (Biggin and Tiian 1989; Ohkuma et al. 1990b). It is also conceivable that additional assembly pathways and functionally distinct classes of core promoter complexes exist and are targeted by yet other regulators or particular combinations of regulators. Because the assays used here distinguish only between productive and nonproductive complexes, in the future it will be necessary to combine quantitative functional assays with structural analysis of core promoter complexes to elucidate the full spectrum of complexes, their composition, and their regulated assembly.

\section{Materials and methods}

\section{Plasmids}

Plasmid $\mathrm{pKS}-\mathrm{P}_{\mathrm{Adh}}$ the standard target plasmid $\mathrm{p}\left(\mathrm{U}+\left.\right|_{2} \mathrm{D}-33 /\right.$ $+3 \mathrm{CAT}$, and the internal control plasmid $\mathrm{pD}-33 /+23 \mathrm{CAT}$ are described in Johnson and Krasnow (1990). In p $\left(U+\left.\right|_{2} D-33 /\right.$ $+3 \mathrm{CAT}$, the homeo domain-binding sites are positioned $47 \mathrm{bp}$ upstream of the $A d h$ transcription start site in the $\mathrm{XbaI}$ site of the vector polylinker. The related plasmids $\mathrm{p}\left(\mathrm{U}+\mathrm{L}_{2}(\mathrm{Pst}) \mathrm{D}-33 /\right.$ $+3 \mathrm{CAT}$ and $\mathrm{p}(\mathrm{U}+)_{2}$ (Hind) $\mathrm{D}-33 /+3 \mathrm{CAT}$ contain the homeo domain-binding sites 58 or 66 bp upstream of the $A d h$ transcription start site in the PStI or HindIII sites, respectively, of the polylinker (see Fig. 2B). pD-33G-less contains an Adh core promoter fragment $(-33$ to +6$)$ generated by PCR amplification of $\mathrm{pD}-33 \mathrm{CAT}$ (England et al. 1990) using the upstream primer P0 (5'-ATTTGCGAGTACGCAAAGCT) and the downstream primer P7 (5'-CGCCCGGGAATAATGCATGACTTGGACCTTC). The amplified fragment was digested with Pst I and $S m a \mathrm{I}$ and inserted between the PstI and SspI sites of $\gamma$-fibrinogen G-less, a pUC19 derivative containing a G-less cassette (Flanagan and Crabtree 1992). The promoter region sequences of new constructs were verified by dideoxy sequencing.

\section{Proteins and nuclear extracts}

EVE protein was purified from an E. coli expressor strain as described previously (Biggin and Tjian 1989), except rifampicin was added to the culture medium at $200 \mu \mathrm{g} / \mathrm{ml}, 6 \mathrm{~min}$ after IPTG addition. Also, the oligonucleotide affinity resin was the same as for the UBX purification, and batch adsorption to the resin was carried out at $4^{\circ} \mathrm{C}$ for $3.5 \mathrm{hr}$. The final preparation was $>95 \%$ pure full-length EVE protein, as determined by SDSPAGE analysis and staining with Coomassie blue or immunoblotting with the $3 \mathrm{Cl} 0$ anti-EVE antibody. Nuclear extracts were prepared from 0 - to 12 -hr old $D$. melanogaster embryos essentially as described in Wampler et al. (1990). UBX protein, the $D$. melanogaster Kc cell nuclear extracts, and protein concentration determination are described in Johnson and Krasnow (1990).

\section{In vitro transcription and transcript analysis}

Standard transcription reactions and primer extension analysis of the transcripts were carried out as described previously (Johnson and Krasnow 1990), with minor modifications. The $25-\mu 1$ reactions were carried out at $22^{\circ} \mathrm{C}$ for $30 \mathrm{~min}$ and contained $32.5 \mathrm{~mm}$ HEPES-K ${ }^{+}(\mathrm{pH} 7.6), 55 \mathrm{~mm} \mathrm{KCl}, 6.25 \mathrm{~mm}$ $\mathrm{MgCl}_{2}, 0.05 \mathrm{~mm}$ EDTA, $1 \mathrm{~mm} \mathrm{DTT}, 5 \%$ (vol/vol) glycerol, 500 $\mu \mathrm{M}$ NTPs, 10 units of RNasin (Promega), $250 \mathrm{ng}$ each of the supercoiled plasmid target template $\mathrm{p}(\mathrm{U}+)_{2} \mathrm{D}-33 /+3$ and the control template $\mathrm{pD}-33 /+23$, and $60 \mu \mathrm{g}$ of $\mathrm{Kc}$ cell nuclear extract protein. Where indicated, $40 \mu \mathrm{g}$ of embryo nuclear extract protein was used in place of the Kc cell nuclear extract. UBX Ib protein (170 ng) and EVE protein ( $300 \mathrm{ng}$, when added, were preincubated with the template for $8 \mathrm{~min}$ at $22^{\circ} \mathrm{C}$ before the addition of the nuclear extract unless indicated otherwise; these amounts of the homeo domain proteins gave maximal regulatory effects (Johnson and Krasnow 1990, and unpubl.). (At higher concentrations of EVE, there was additional repression of the target template, but there was also an effect on the internal control template such that their relative expression levels remained constant.) Transcription reactions were terminated by the addition of $200 \mu \mathrm{l}$ of termination buffer (Johnson and Krasnow 1990) that contained proteinase $\mathrm{K}$ at $0.1 \mathrm{mg} / \mathrm{ml}$ and a standard amount of RNA derived from in vitro transcription by $\mathrm{T} 3$ RNA polymerase of $\mathrm{pKS}-\mathrm{P}_{\mathrm{Adh}}$ linearized with $\mathrm{BamHI}$. Terminated reactions were incubated at $37^{\circ} \mathrm{C}$ for $10 \mathrm{~min}$, and the in vitro transcription products were extracted, precipitated, and analyzed by primer extension using the CAT5'ORF primer $\left(5^{\prime}\right.$ GGTATATCCAGTGATTTTTTTCTCC). The primer corresponds to sequences near the $5^{\prime}$ end of the CAT gene-coding sequence in pC4CAT (Thummel et al. 1988) and gives extension products of $\sim 75, \sim 95$, and $\sim 200$ nucleotides for transcripts of the target and control templates and for the RNA standard, respectively. Dried gels were quantitated using an AMBIS radioanalytic scanner, and absolute transcript levels were calculated from the amount of primer converted to extension product. Best-fit first-order reaction curves were derived from linear regression analysis of semilogarithmic transforms of the timecourse data.

\section{Sarkosyl inhibition experiments and preIC formation reactions}

Prior to the studies of preIC formation, the Sarkosyl ( $N$-lauroylsarcosine) sensitivities of the different stages of transcription were determined by the strategy of Hawley and Roeder (1985, 1987). Low concentrations [0.03\% (wt/vol)] of Sarkosyl prevented formation of preICs; but once formed, transcription initiated efficiently at concentrations up to $0.06 \%$. Elongating transcription complexes were resistant to at least $0.4 \%$ Sarkosyl. These results for Kc cell nuclear extracts are similar to 
results with nuclear extracts of $D$. melanogaster embryos $(\mathrm{Ka}$ donaga 1990).

PreIC formation reactions were performed as described above for in vitro transcription reactions except that NTPs were omitted from the initial incubation to prevent transcription but allow preIC formation. Also, the initial volume of the reaction was reduced to $20 \mu \mathrm{l}$ and the concentrations of the various components correspondingly increased to compensate for the volume of the subsequent additions. After the initial incubation at $22^{\circ} \mathrm{C}$ for the times indicated in the figure legends, $2.5 \mu \mathrm{l}$ of $0.35 \%$ (wt $/ \mathrm{vol}$ ) Sarkosyl was added to prevent further formation of preICs, followed 15 or $30 \mathrm{sec}$ later by the addition of $2.5 \mu \mathrm{l}$ of a $5 \mathrm{~mm}$ solution of all four NTPs to allow a single round of transcription from the preformed preICs. Sarkosyl was omitted in experiments to test multiround transcription (Fig. 7). After NTP addition, incubations continued for $30 \mathrm{~min}$ unless otherwise noted, and the reactions were stopped and analyzed by primer extension. Under standard conditions, initiation and elongation were complete by $3 \mathrm{~min}$ after NTP addition.

Competitor oligonucleotide added following preIC formation (Fig. 3B) was the annealed oligonucleotides AGCT(ATT) ${ }_{12}$ and AGCT(AAT) ${ }_{12}$ in $5 \mu$ l of buffer O [10 mM Tris (pH 8.0), $1 \mathrm{~mm}$ EDTA, $50 \mathrm{~mm} \mathrm{NaCl}$. Template cleavage following preIC formation (Fig. 3C) was carried out with 75 units each of PstI and $X b a I$ restriction enzymes (New England Biolabs).

\section{DNase I protection assay}

DNase I protection experiments were performed using a method based on Gralla (1985) in which an indirect end-labeling technique is used to visualize the probe DNA after the treatment with nuclease. Homeo domain proteins and extract proteins were mixed with the templates and incubated under the conditions described above for preIC formation except that RNasin was omitted. Also, because the primers used for indirect end-labeling were complementary to vector sequences present in both the target and control templates, $150 \mathrm{ng}$ of $\mathrm{pD}-33 \mathrm{G}$ less and $100 \mathrm{ng}$ of pUC18 were substituted for the standard control plasmid. This kept the DNA concentration and the number of $A d h$ promoters the same as under standard conditions and allowed visualization of binding to the target template alone. After an initial incubation for the times indicated in the figure legends, $300 \mathrm{ng}$ (Fig. 3B) or $500 \mathrm{ng}$ (Figs. 2 and 5) of DNase I was added in $3 \mu \mathrm{l}$ of buffer $\mathrm{D}\left[7.7 \mathrm{mM} \mathrm{CaCl}, 7 \mathrm{mM} \mathrm{MgCl}_{2}, 30\right.$ mM HEPES-K ${ }^{+}(\mathrm{pH} 7.6), 1 \mathrm{~mm}$ DTT, 6.25\% (vol/vol) glycerol, and $5 \mu \mathrm{g} / \mathrm{ml}$ bovine senum albumin]. After $40 \mathrm{sec}$ at $22^{\circ} \mathrm{C}$, reactions were terminated by the addition of $200 \mu \mathrm{l}$ of stop solution $[0.5 \%$ SDS, $15 \mathrm{~mm}$ EDTA, $25 \mathrm{~mm}$ Tris- $\mathrm{Cl}$ (pH 8.0), $300 \mathrm{~mm}$ $\mathrm{NaCl}$, and $200 \mu \mathrm{g} / \mathrm{ml}$ proteinase $\mathrm{K}$ ] and then incubated at $37^{\circ} \mathrm{C}$ for $10 \mathrm{~min}$. Samples were extracted twice with phenol/chloroform/isoamyl alcohol $(25: 24: 1)$ and precipitated with 2.2 volumes of ethanol. The samples were then resuspended in $100 \mu \mathrm{l}$ of $0.3 \mathrm{M}$ sodium acetate containing $5 \mathrm{ng}$ of ${ }^{32} \mathrm{P}$-end-labeled primer $\left(\sim 10^{6} \mathrm{cpm}\right)$ and reprecipitated with $300 \mu \mathrm{l}$ of ethanol. After rinsing with $85 \%$ ethanol, samples were resuspended in $10 \mu$ l of hybridization buffer [10 $\mathrm{mm}$ Tris $-\mathrm{Cl}(\mathrm{pH} 8.3), 10 \mathrm{mM}$ $\mathrm{MgCl}_{2}$, and $50 \mathrm{~mm} \mathrm{NaCl}$, heated to $95^{\circ} \mathrm{C}$ for $3 \mathrm{~min}$, and allowed to hybridize for $15 \mathrm{~min}$ at $45^{\circ} \mathrm{C}$. Twenty microliters of extension buffer [10 mM Tris-Cl (pH 8.3), 0.75 mм EDTA, 5 mм DTT, 375 $\mu \mathrm{M}$ dNTPs] containing $0.1 \mathrm{U} / \mu \mathrm{l}$ of DNA polymerase I large fragment (New England Biolabs) was prewarmed briefly to $45^{\circ} \mathrm{C}$ and then added to the samples. After incubation at $55^{\circ} \mathrm{C}$ for 10 min, products were precipitated by the addition of $30 \mu \mathrm{l}$ of 0.6 M sodium acetate and $180 \mu \mathrm{l}$ ethanol, and analyzed by electrophoresis through $6 \%$ polyacrylamide gels containing $7.8 \mathrm{M}$ urea. The high temperature of the primer extension reaction mini- mized premature terminations. The coding strand primer was CAT5'ORF, and the noncoding strand primer was 5'PE $\left(5^{\prime}\right.$ AGACGAAATTATTTTTAAAG) in Figure 2 and P0 in Figure $5 ; 5^{\prime} \mathrm{PE}$ and $\mathrm{P0}$ are from $\mathrm{pC} 4 \mathrm{CAT}$ vector sequences upstream of the Adh promoter.

\section{Acknowledgments}

We thank Mark Biggin for helpful discussions and communication of unpublished results and for advice on EVE purification, and Nipam Patel, Mike Flannagan, and Mark Biggin for antibodies and plasmids. We are grateful to the members of this laboratory and to Dan Hershlag and Paul Mitsis for helpful discussions and comments on the manuscript. F.B.J. was supported by the Medical Scientist Training Program of the National Institutes of Health. M.A.K is a Lucille P. Markey Scholar in Biomedical Science. This work was supported by grants from the Lucille P. Markey Charitable Trust and the National Institutes of Health to M.A.K.

The publication costs of this article were defrayed in part by payment of page charges. This article must therefore be hereby marked "advertisement" in accordance with 18 USC section 1734 solely to indicate this fact.

\section{References}

Abmayr, S.M., J.L. Workman, and R.G. Roeder. 1988. The pseudorabies immediate early protein stimulates in vitro transcription by facilitating TFIID : promoter interactions. Genes \& Dev. 2: 542-553.

Ayer, D.E. and W.S. Dynan. 1990. A downstream-element-binding factor facilitates assembly of a functional preinitiation complex at the simian virus 40 major late promoter. Mol. Cell. Biol. 10: 3635-3645.

Beachy, P.A. 1990. A molecular view of the Ultrabithorax homeotic gene of Drosophila. Trends Gene. 6: 46-51.

Biggin, M.D. and R. Tjian. 1989. A purified Drosophila homeodomain protein represses transcription in vitro. Cell 58: $433-440$.

Bunick, D., R. Zandomeni, S. Ackerman, and R. Weinmann. 1982. Mechanism of RNA polymerase II-specific initiation of transcription in vitro: ATP requirement and uncapped runoff transcripts. Cell 29: 877-886.

Carcamo, J., S. Lobos, A. Merino, L. Buckbinder, R. Weinmann, V. Natarajan, and D. Reinberg. 1989. Factors involved in specific transcription by mammalian RNA polymerase II. $J$. Biol. Chem. 264: 7704-7714.

Conaway, R.C. and J.W. Conaway. 1988. ATP activates transcription initiation from promoters by RNA polymerase II in a reversible step prior to RNA synthesis. J. Biol. Chem. 263: 2962-2968.

Croston, G.E., L.A. Kerrigan, L.M. Lira, D.R. Marshak, and J.T. Kadonaga. 1991. Sequence-specific antirepression of histone H1-mediated inhibition of basal RNA polymerase II transcription. Science 251: 643-649.

Doe, C.Q., D. Smouse, and C.S. Goodman. 1988. Control of neuronal fate by the Drosophila segmentation gene evenskipped. Nature 333: 376-378.

England, B.P., U. Heberlein, and R. Tjian. 1990. Purified Drosophila transcription factor, $A d h$ distal factor-1 (Adf-1), binds to sites in several Drosophila promoters and activates transcription. J. Biol. Chem. 265: 5086-5094. 
Flanagan, M.R. and G.R. Crabtree. 1992. In vitro transcription faithfully reflecting T-cell activation requirements. $/$. Biol. Chem. 267: 399-406.

Gralla, J.D. 1985. Rapid "footprinting" on supercoiled DNA. Proc. Natl. Acad. Sci. 82: 3078-3081.

Hafen, E., M. Levine, and W.J. Gehring. 1984. Regulation of Antennapedia transcript distribution by the bithorax complex in Drosophila. Nature 307: 287-289.

Hai, T., M. Horikoshi, R.J. Roeder, and M.R. Green. 1988. Analysis of the role of the transcription factor ATF in the assembly of a functional preinitiation complex. Cell 54: 10431051.

Han, K., M.S. Levine, and J.L. Manley. 1989. Synergistic activation and repression of transcription by Drosophila homeobox proteins. Cell 56: 573-583.

Harding, K., Rushlow, C., Doyle, H.J., Hoey, T., and M. Levine. 1986. Cross-regulatory interactions among pair-rule genes in Drosophila. Science 233: 953-959.

Hawley, D.K. and R.G. Roeder. 1985. Separation and partial characterization of three functional steps in transcription initiation by human RNA polymerase II. I. Biol. Chem. 260: $8163-8172$.

- 1987. Functional steps in transcription initiation and reinitiation from the major late promoter in a HeLa nuclear extract. J. Biol. Chem. 262: 3452-3461.

Hayashi, S. and M.P. Scott. 1990. What determines the specificity of action of Drosophila homeodomain proteins? Cell 63: 883-894.

Hogness, D.S., H.D. Lipshitz, P.A. Beachy, D.A. Peattie, R.B. Saint, M. Goldschmidt-Clermont, P.J. Harte, E.R. Gavis, and S.L. Helfand. 1985. Regulation and products of the Ubx domain of the bithorax complex. Cold Spring Harbor Symp. Quant. Biol. 50: 181-194.

Jaynes, J.B. and P.H. O'Farrell. 1991. Active repression of transcription by the engrailed homeodomain protein. EMBO I. 10: $1427-1433$.

Johnson, F.B. and M.A. Krasnow. 1990. Stimulation of transcription by an Ultrabithorax protein in vitro. Genes \& Dev. 4: 1044-1052.

Kadonaga, J.T. 1990. Assembly and disassembly of the Drosophila RNA polymerase II complex during transcription. $J$. Biol. Chem. 265: 2624-2631.

Katagiri, F., K. Yamazaki, M. Horikoshi, R.G. Roeder, and N.-H. Chua. 1990. A plant DNA-binding protein increases the number of active preinitiation complexes in a human in vitro transcription system. Genes \& Dev. 4: 1899-1909.

Kato, H., M. Horikoshi, and R.G. Roeder. 1991. Repression of HIV-1 transcription by a cellular protein. Science 25: 14761479.

Keleher, C.A., C. Goutte, and A.D. Johnson. 1988. The yeast cell-type-specific repressor alpha2 acts cooperatively with a non-cell-type-specific protein. Cell 53: 927-936.

Kerrigan, L.A., G.E. Croston, L.M. Lira, and J.T. Kadonaga. 1991. Sequence-specific transcriptional antirepression of the Drosophila Kruppel gene by the GAGA factor. J. Biol. Chem. 266: 574-582.

Kornberg, R.D. and Y. Lorch. 1991. Irresistible force meets immovable object: Transcription and the nucleosome. Cell 67: 833-836.

Krasnow, M.A., E.E. Saffman, K. Kornfeld, and D.S. Hogness. 1989. Transcriptional activation and repression by Ultrabithorax proteins in cultured Drosophila cells. Cell 57: 1031-1043.

Levine, M. and J.L. Manley. 1989. Transcriptional repression of eukaryotic promoters. Cell 59: 405-408.

Lewis, E.B. 1978. A gene complex controlling segmentation in
Drosophila. Nature 276: 565-570.

Lin, Y.-S. and M.R. Green. 1991. Mechanism of action of an acidic transcription activator in vitro. Cell 64: 971-981.

Lue, N.F., D.I. Chasman, A.R. Buchman, and R.D. Kornberg. 1987. Interaction of $\mathrm{Gal} 4$ and $\mathrm{Gal} 80$ gene regulatory proteins in vitro. Mol. Cell. Biol. 7: 3446-3451.

Meisterernst, M. and R.G. Roeder. 1991. Family of proteins that interact with TFIID and regulate promoter activity. Cell 67: $557-567$.

Nüsslein-Volhard, C., H. Kluding, and G. Jürgens. 1985. Genes affecting the segmental subdivision of the Drosophila embryo. Cold Spring Harbor Symp. Quant. Biol. 50: 145-154.

Ohkuma, Y., M. Horikoshi, R.G. Roeder, and C. Desplan. 1990a. Engrailed, a homeodomain protein, can repress in vitro transcription by competition with the TATA box-binding protein transcription factor IID. Proc. Natl. Acad. Sci. 87: 22892293.

- $1990 \mathrm{~b}$. Binding site dependent activation and repression of in vitro transcription by Drosophila homeodomain proteins. Cell 61: 475-484.

Rio, D., A. Robbins, R. Myers, and R. Tijan. 1980. Regulation of simian virus 40 early transcription in vitro by a purified tumor antigen. Proc. Natl. Acad. Sci. 77: 5706-5710.

Roeder, R.G. 1991. The complexities of eukaryotic initiation: Regulation of preinitiation complex assembly. Trends Biochem. Sci. 16: 402-408.

Rougvie, A.E. and J.T. Lis. 1988. The RNA polymerase II molecule at the $5^{\prime}$ end of the uninduced hsp70 gene of D. melanogaster is transcriptionally engaged. Cell 54: 795-804.

Sampson, M.-L., L. Jackson-Grusby, and R. Brent. 1989. Gene activation and DNA binding by Drosophila $U b x$ and $a b d-A$ proteins. Cell 57: 1045-1052.

Sawadogo, M. and R.G. Roeder. 1984. Energy requirement for specific transcription initiation by the human RNA polymerase II system. J. Biol. Chem. 259: 5321-5326.

- 1985. Interaction of a gene-specific transcription factor with the adenovirus major late promoter upstream of the TATA box region. Cell 43: 165-175.

Schmidt, M.C., Q. Zhou, and A.J. Berk. 1989. Spl activates transcription without enhancing DNA-binding activity of the TATA box factor. Mol. Cell Biol. 9: 3299-3307.

Thali, M., M.M. Muller, M. DeLorenzi, P. Matthias, and M. Bienz. 1988. Drosophila homeotic genes encode transcriptional activators similar to mammalian OTF-2. Nature 336: 598-601.

Thummel, C.S., A.M. Boulet, and H.D. Lipshitz. 1988. Vectors for Drosophila P element-mediated transformation and tissue culture transfection. Gene 74: 445-456.

Tremml, G. and M. Bienz. 1989. An essential role of evenskipped for homeotic gene expression in the Drosophila visceral mesoderm. EMBO /. 8: 2687-2693.

Van Dyke, M.W., R.G. Roeder, and M. Sawadogo. 1988. Physical analysis of transcription preinitiation complex assembly on a class II gene promoter. Science 241: 1335-1338.

Wampler, S.L., C.M. Tyree, and J.T. Kadonaga. 1990. Fractionation of the general RNA polymerase II transcription factors from Drosophila embryos. I. Biol. Chem. 265: 21223-21231.

Workman, J.L., R.G. Roeder, and R.E. Kingston. 1990. An upstream transcription factor, USF (MLTF) facilitates the formation of preinitiation complexes during in vitro chromatin assembly. EMBO /. 9: 1299-1308. 


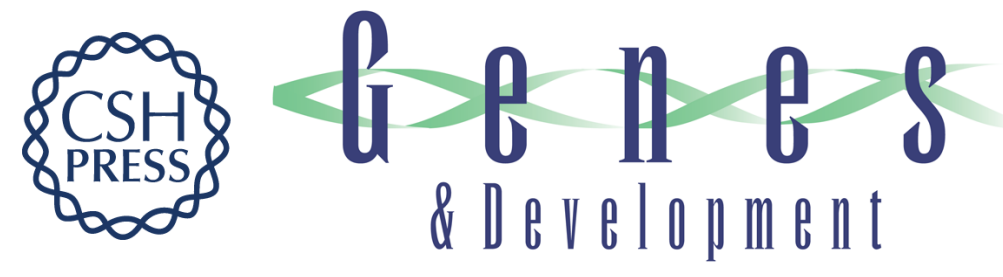

\section{Differential regulation of transcription preinitiation complex assembly by activator and repressor homeo domain proteins.}

F B Johnson and M A Krasnow

Genes Dev. 1992, 6:

Access the most recent version at doi:10.1101/gad.6.11.2177

References This article cites 50 articles, 23 of which can be accessed free at: http://genesdev.cshlp.org/content/6/11/2177.full.html\#ref-list-1

License

Email Alerting

Receive free email alerts when new articles cite this article - sign up in the box at the top Service right corner of the article or click here.

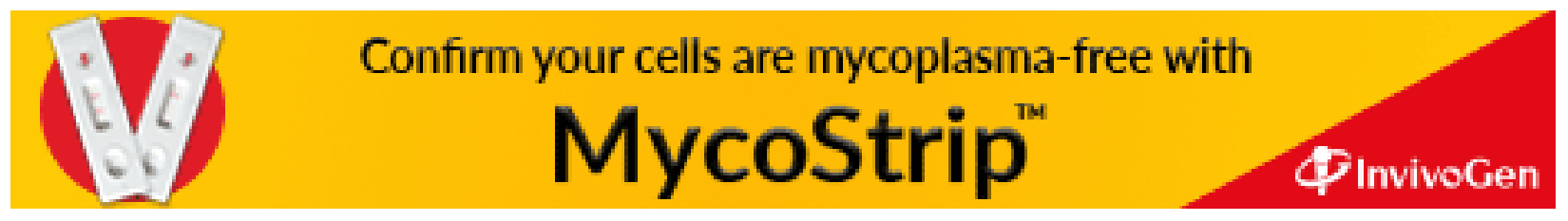

